\title{
Nox emission modelling from industrial steam boilers
}

\begin{abstract}
Previous researches often emphasize on the sources and effects of air pollutants in the environment and human population. A part of those studies were done in order to explore the spread or distribution pattern of those pollutants, especially regarding the emission from industrial steam boilers. It is very important to evaluate the transfer trend of air pollutants at both local and global scales. In this study, Industrial Source Complex Short Term Version 3 (ISCST3) model has been used to predict the distribution of NOx emitted from industrial steam boilers in the District of Hulu Langat, Selangor. The result of analyses indicates that the emission rates for steam boilers were ranging from $0.0083 \mathrm{~kg}$ NOx/hour to as high as 0.2771 $\mathrm{kg} \mathrm{NOx} /$ hour while the total emission load was $1.9969 \mathrm{~kg}$ NOx/hour. The evaluation on dispersion contour shows that the concentration of NOx was higher in 1-hour reading than 24hour value. The highest concentration of NOx was predicted to be within $104.65 \mathrm{~km} 2$ from the sources of NOx (steam boilers).
\end{abstract}

Keyword: Air pollutant; Industrial steam boilers; NOx emission; Industrial source complex short term version 3; Distribution pattern 